\title{
Cuerpo extraño intraabdominal
}

\author{
Molero Silvero E. ${ }^{1}$, Bartolomé Cela E. ${ }^{2}$, Pérez Alé M. ${ }^{3}$, García de la Llana MA. ${ }^{4}$
}

Sanid. mil. 2015; 71 (2): 117-118; ISSN: 1887-8571

\section{PRESENTACIÓN}

Mujer de 81 años de edad con antecedentes personales de alergia a la codeína, hipertensión arterial y dislipemia.

Hace dos años fue intervenida quirúrgicamente de histerectomía con doble anexectomía por historia de metrorragia de 5 horas de evolución, objetivándose masa exofítica, friable y sangrante que salía de cavidad uterina y llegaba casi a vulva. El estudio anatomopatológico informó de pólipo endometrial con displasia focal.

Acude al servicio de Urgencias refiriendo cuadro de un mes de evolución de dolor abdominal continuo en fosa ilíaca derecha, no irradiado y acompañado de náuseas, distermia, anorexia y pérdida de aproximadamente 7 kilos de peso en los últimos meses.

Aporta TC abdominal (Figs. 1 y 2), en el que, a nivel de FID se identifica una colección de $65 \times 54 \times 79 \mathrm{~mm}$ de pared engrosada, con contenido metálico en su interior y densidad radiológica en 'miga de pan', en amplio contacto con la pared abdominal, desplazando las asas de íleon distal, y con efecto masa sobre el ciego y válvula ileocecal sin signos compresivos.

Ante dichos hallazgos, se decide ingreso para realización de intervención quirúrgica, objetivándose dos perforaciones a nivel de yeyuno y gran plastrón adherido a pared abdominal que se encuentra disecada a nivel de colon derecho.

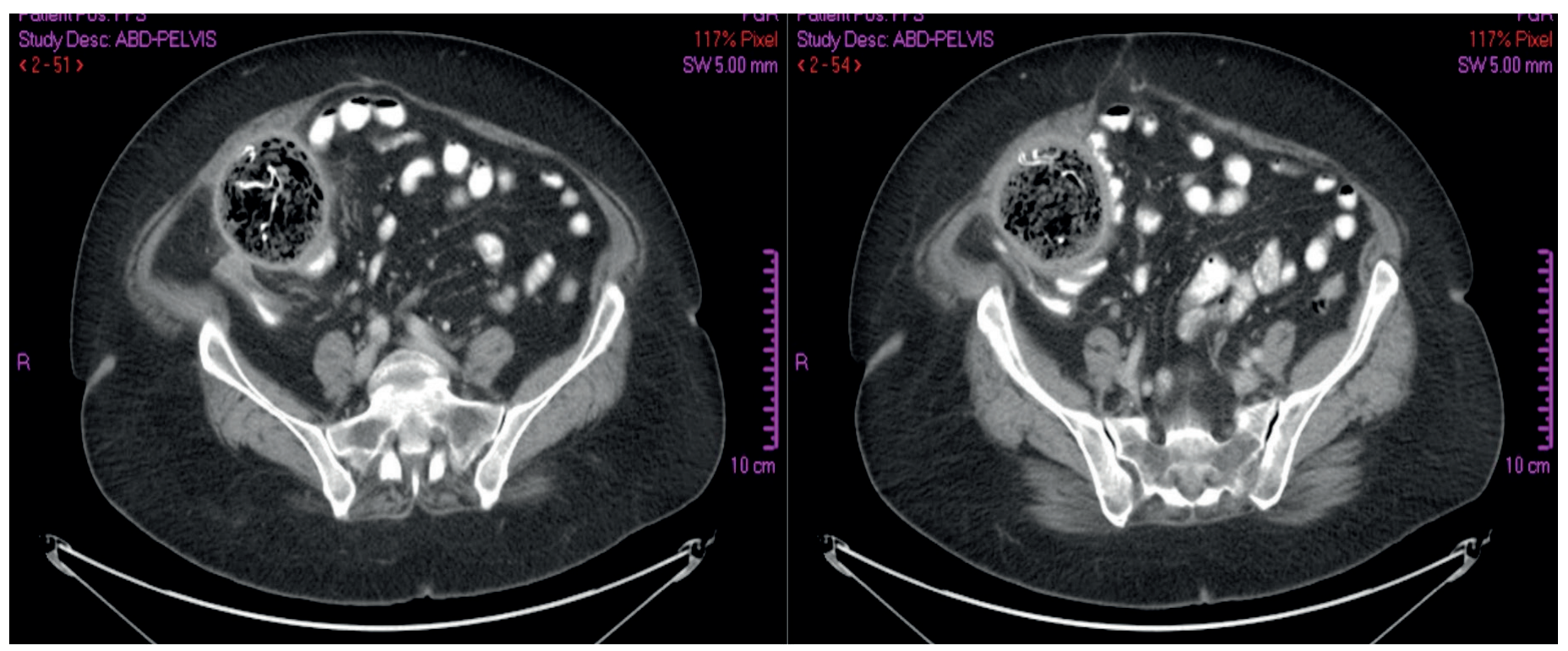

Figuras 1 y 2. Imágenes de TC abdominal. Se evidencia cuerpo extraño con contenido metálico en su interior en fosa ilíaca derecha.

${ }^{1}$ MIR $5^{\circ}$ año. Servicio de Medicina Intensiva.

2 Tcol Médico. Servicio de Medicina Intensiva.

${ }^{3}$ Cte médico. Servicio de Medicina Intensiva.

${ }^{4}$ Col. Médico. Servicio de Medicina Intensiva.

Hospital Central de la Defensa Gómez Ulla.

Dirección para correspondencia: Esperanza Molero Silvero. Servicio de Medicina Intensiva. Hospital Central de la Defensa Gómez Ulla. Glorieta del Ejército, s/n. 28047 Madrid. España.emolsil@oc.mde.es

Recibido: 16 de enero de 2015.

Aceptado: 16 de marzo de 2015. 


\section{Diagnóstico: "gosipiboma" o "textiloma"}

\section{DISCUSIÓN}

Se realiza extracción del cuerpo extraño por una de las perforaciones, puesto que tenía localización intracolónica y posteriormente se practica hemicolectomía derecha incluyendo un metro de intestino delgado por adherencias firmes.

La paciente presenta buena evolución clínica y radiológica posterior (Figs 3 y 4), pudiendo ser dada de alta a domicilio con controles posteriores satisfactorios.

El "gosipiboma" o "textiloma" es una masa que está compuesta por material quirúrgico no absorbible y con una matriz de algodón ${ }^{1}$. Su incidencia es desconocida aunque se estima que ocurre en 1:100 a 1:5000 intervenciones quirúrgicas ${ }^{2}$, siendo la localización abdominal la más frecuente (aproximadamente un $55 \%)^{3}$. La clínica, puede presentarse de forma aguda, principalmente en forma de sepsis, granuloma o absceso o bien retardada (incluso años después de la cirugía) con dolor, masa, oclusión intestinal, peritonitis, fistulización, sangrado, etc ct,5 $^{3,5}$ El "textiloma" puede ser demostrado mediante ecografía como una masa de contenido lineal, ondulado y líquido, de centro ecogénico y con sombra sónica posterior, pudiendo estar asociada a gas y/o calcificaciones. En ocasiones, puede verse una imagen totalmente anecoica de contenido líquido con ecos internos irregulares y de tamaños diferentes o bien patrones de hipoecogenicidad o, incluso, visualizarse como masa compleja ${ }^{1,4,6}$.

En la TC se puede apreciar una masa bien delimitada con pared densa que puede presentar refuerzo post-contraste in- travenoso. El centro lesional tiene una apariencia de remolino ("whirl-like" pattern) y se atribuye a gas atrapado dentro de las fibras del material textil. Si se demuestra niveles hidroaéreos o gas en su interior, es indicativo de la presencia de absceso (debiendo hacer diagnóstico diferencial con hematoma). En ocasiones, dicha masa puede calcificarse o, incluso, crear un trayecto fistuloso ${ }^{1,4,6}$.

El tratamiento siempre debe ser quirúrgico, incluso si ha sido hallazgo casual en prueba de imagen por otro proceso debido a las graves complicaciones que pueden presentar $^{3}$.

\section{BIBLIOGRAFÍA}

1. Motta Ramírez, G. A., González Burgos, O., Castillo Lima. J. A., Evaristo Villalobos García, E. Material quirúrgico olvidado: Gossypiboma, textiloma, gasoma. Anales de Radiología México 2007;4:285-296.

2. Sarda AK, Pandey D, Neogi S, et al. PO complications due to a retained surgical sponge. Singapore Med J 2007; 48:e160-e164.

3. Contreras-Ruiz VR. Textiloma. An Med (Mex) 2007; 52 (1): 37-41.

4. Haegeman, S., Maleuxm, G., Heye, S., Daenens, K. Textiloma complicated by abscess-formation, three years after surgical repair of abdominal aortic aneurysm. JBR-BTR, 2008, 91: 51-53.

5. Al-Farah RehmatUllah, Samia Shuja ,Sanaullah Gazozai. Intra-Abdominal Surgical Gauze pseudotumor (Gossypiboma) Mimicking A Dermoid Cyst. International Journal of Pathology; 2012; 10(2):85-87

6. Nevzat Karabulut, Duygu Herek, Yılmaz Kıroğlu. CT of intrathoracic gossypiboma (textiloma). Diagn Interv Radiol DOI 10.4261/1305-3825.DIR.312009.0.

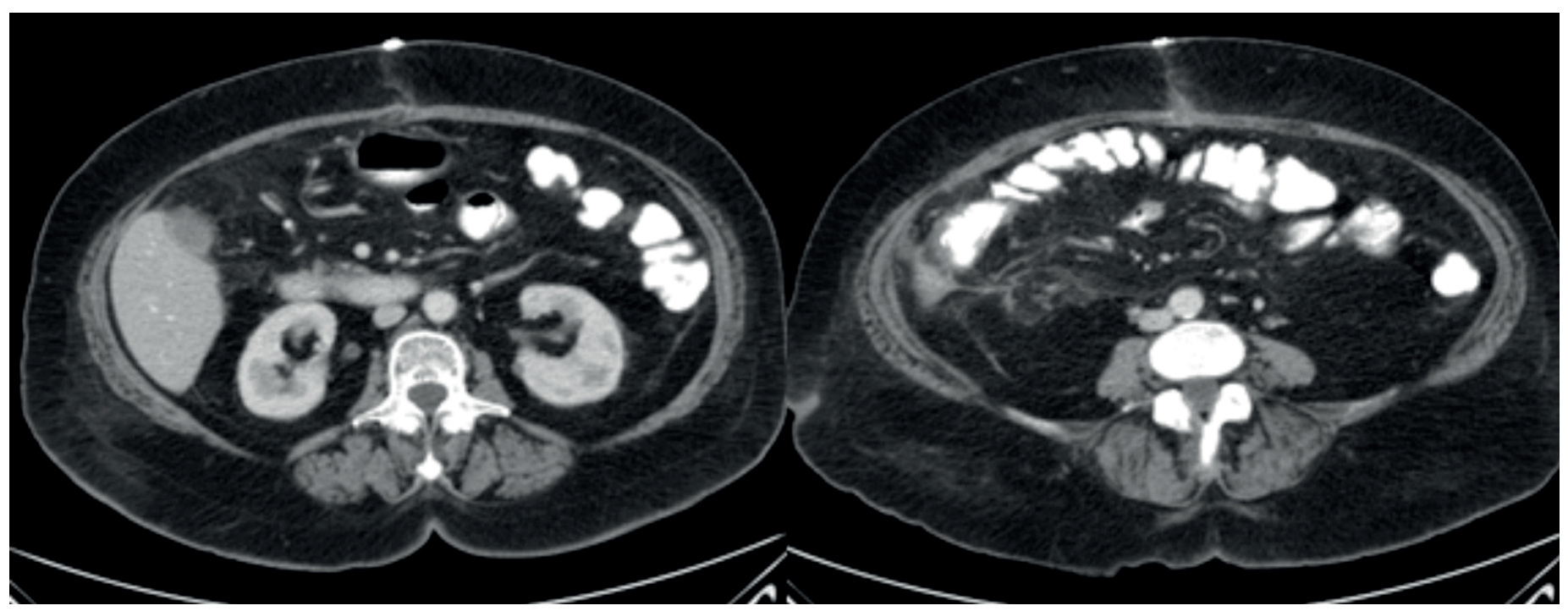

Figuras 3 y 4. Control radiológico tras la extracción del cuerpo extraño y hemicolectomía derecha. 